c) American Dairy Science Association, 2003.

\title{
Plasmin Activity in Pressurized Milk
}

\author{
M. R. García-Risco, I. Recio, E. Molina, and R. López-Fandiño \\ Instituto de Fermentaciones Industriales (CSIC) \\ Juan de la Cierva, 3, 28006 Madrid, Spain
}

\section{ABSTRACT}

The effects of pressure (up to $400 \mathrm{MPa}$ ), applied at room temperature, on native proteinase activity of milk were investigated by means of plasmin activity, plasmin-derived activity after plasminogen activation and their distribution in different milk fractions, micelle microstructure, $\beta$-LG denaturation, and casein susceptibility to proteolytic attack. The pressure conditions assayed did not lead to plasmin inactivation and only decreased around 20 to $30 \%$ total plasmin activity after plasminogen activation. However, pressure caused severe disruption of the micellar structure, releasing high levels of caseins, plasmin, and plasminogen to the soluble fraction of milk. High levels of soluble denatured $\beta$ LG were also found in the ultracentrifugation supernatants of pressurized milks, particularly in those treated at $400 \mathrm{MPa}$. Probably as a result of micellar disintegration, caseins became more susceptible to proteolysis by exogenous plasmin. However, no enhanced proteolytic degradation was observed when we compared the evolution of pressurized and unpressurized milks during refrigerated storage. Serum-liberated plasmin may become more vulnerable to the action of proteinase inhibitors leading to a reduced proteolysis on refrigerated storage, despite the increased susceptibility of caseins to proteinase action.

(Key words: milk, plasmin system, micelle microstructure, $\beta$-LG denaturation)

Abbreviation key: $\mathbf{C E}=$ capillary electrophoresis, $\varepsilon$ ACA $=\varepsilon$-aminocaproic acid.

\section{INTRODUCTION}

The main native milk proteinase, plasmin, plays a very important role in the functional properties of dairy products, as it affects cheese yield, proteolysis during cheese ripening, yogurt quality, and keeping quality of UHT milk on storage (Bastian and Brown, 1996).

Received July 15, 2002.

Accepted October 1, 2002.

Corresponding author: Rosina López-Fandiño; e-mail: rosina@ ifi.csic.es.
Plasmin, as well as its zymogen, plasminogen, are highly heat resistant, but plasmin activity in milk is driven by a complex system of activators and inhibitors with different heat stabilities. Treatment of milk at $72^{\circ} \mathrm{C}$ for $15 \mathrm{~s}$ inactivates plasmin by about 10 to $17 \%$; however, it has been demonstrated that certain pasteurization conditions enhance proteolysis during subsequent storage, which was attributed to the thermal degradation of inhibitors operating in the plasmin system (Grufferty and Fox, 1988). In UHT milk, a heat treatment of $142^{\circ} \mathrm{C}$ for $18 \mathrm{~s}$ is necessary to completely prevent proteolysis by plasmin during storage of the product (Grufferty and Fox, 1988).

High pressure is gaining increasing acceptance as a food-processing technique because it exerts antimicrobial effects and causes reversible and irreversible changes in enzymatic activities, but the sensory and nutritional quality of food is not affected (Huppertz et al., 2002). In milk, plasmin activity was shown to resist at least $400 \mathrm{MPa}$ applied for $30 \mathrm{~min}$ at $25^{\circ} \mathrm{C}$ (LópezFandiño et al., 1996), while these conditions reduced the total plasmin activity after plasminogen activation by 25\% (García-Risco et al., 1998). Pressurization at higher temperatures considerably increased plasmin inactivation in milk, which reached $86.5 \%$ after treatments at $60^{\circ} \mathrm{C}$ (García-Risco et al., 2000). Plasmin was also barostable in buffer at room temperature, resisting up to $600 \mathrm{MPa}$ for $20 \mathrm{~min}$, but it was significantly inactivated at $400 \mathrm{MPa}$ in the presence of $\beta$-LG (Scollard et al., 2000a).

Native proteinase activity in pressurized milk could also be driven by factors other than plasmin and plasminogen barostabilities. Pressurization at room temperature causes micellar disintegration and produces casein solubilization (López-Fandiño et al., 1998; Needs et al., 2000), although pressure treatments at temperatures over $40^{\circ} \mathrm{C}$ progressively increase micelle dimensions (García-Risco et al., 2000). When milk is pressure treated at room temperature, micelle disruption might enhance the susceptibility of casein to proteolysis by increasing the protein surface area available to the enzyme and the exposure of new substrate sites. Furthermore, these changes could also dissociate plasmin and plasminogen, normally attached to the casein micelles (Grufferty and Fox, 1988), to the serum. On the other 
hand, treatment of milk at pressures higher than 100 $\mathrm{MPa}$ induces $\beta$-LG denaturation, which increases with the temperature of the treatment (López-Fandiño et al., 1996; López-Fandiño and Olano, 1998), and unfolded $\beta$ LG can be a potent inhibitor of plasmin through thioldisulfide bonding (García-Risco et al., 1998; Scollard et al., 2000a; Grufferty and Fox, 1988).

The objective of this work was to estimate the effects of pressure, applied at room temperature, on native proteolytic activity in milk. For this purpose, we have examined plasmin activity as well as plasmin-derived activity after plasminogen activation and their distribution in different milk fractions, micelle structure, $\beta$ LG denaturation, and casein susceptibility to proteolytic attack in pressurized and unpressurized milk.

\section{MATERIALS AND METHODS}

\section{High-Pressure Treatments}

Raw milk, collected from a local dairy farm, was skimmed by heating at $30^{\circ} \mathrm{C}$ for $30 \mathrm{~min}$, centrifuged at $4500 \times g$ for $20 \mathrm{~min}$ at $20^{\circ} \mathrm{C}$, and filtered through glasswool. Milk was poured into 70-ml polyethylene bottles, avoiding any headspace, and pressurized at 100 to 400 MPa for 15 min (900 HP Eurotherm Automation, 69572 Dardilly Cedex, Lyon, France). The pressure was raised and released at a rate of $2.5 \mathrm{MPa} / \mathrm{s}$. The temperature of the high-pressure treatment was $23 \pm 2^{\circ} \mathrm{C}$, and it was controlled by circulating water through a jacket surrounding the pressure vessel. The experiments were repeated three times with milk from different batches, and every analytical determination was performed at least in triplicate.

\section{Electron Microscopy}

Unpressurized and pressurized liquid milk samples $(5 \mathrm{ml})$ were mixed with $5 \mathrm{ml}$ of $3 \%$ (wt/vol) agar solution. The mixture was poured on a petri dish, allowed to solidify, and cut into strips of $1 \times 10 \times 10 \mathrm{~mm}^{3}$, approximately. The strips were fixed for $3 \mathrm{~h}$ in $2.5 \%$ (vol/vol) glutaraldehyde in PBS $(\mathrm{pH} 7.0)$ at $4^{\circ} \mathrm{C}$, rinsed three times with PBS, and kept refrigerated overnight in PBS. Then the strips were postfixed in $1 \%$ (wt/vol) osmiun tetroxide (Sigma Chemical Co., St. Louis, MO) for $1 \mathrm{~h}$, rinsed three times with bidistilled water, and dehydrated with increasing concentrations of acetone $(40,60,70,90,95$, and $100 \%)$. Finally, they were infiltrated four times with a solution containing acetone and Spurr's epoxi resin (Sigma Chemical Co.) in proportions ranging from 3:1 acetone:resin to $100 \%$ resin, hardened for $72 \mathrm{~h}$ at $65^{\circ} \mathrm{C}$, and cut into thin sections that were poststained with $2 \%$ uranyl acetate and Reynolds lead citrate. These were examined with a transmission elec- tron microscope (Zeiss 902, Carl Zeiss, Oberkochen, Germany) operated at $80 \mathrm{kV}$. Micellar sizes were measured manually in $12 \times 15 \mathrm{~cm}$ sections of the photographs taken at 50,000 $\times$ magnification.

\section{Protein Distribution Between Different Milk Fractions}

Unpressurized and pressurized milk samples were ultracentrifuged at $100,000 \times g$ for $1 \mathrm{~h}$ at $4^{\circ} \mathrm{C}$ in a Beckman L-70 preparative ultracentrifuge (Beckman Instruments Inc., San Ramon, CA) using a type $70 \mathrm{Ti}$ rotor. The supernatants were carefully removed and filtered through paper Whatman 41. Aliquots of the ultracentrifugation supernatants were treated with 2 $M \mathrm{HCl}$ to $\mathrm{pH} 4.6$, followed by centrifugation at 4500 $\times g$ for $15 \mathrm{~min}$ and filtration through Whatman 41 . Denaturation of $\beta$-LG was calculated from the reduction in peak area following $\mathrm{pH}$ adjustment to 4.6.

Capillary electrophoresis (CE) was performed as described by Recio and Olieman (1996) with a Beckman P/ACE System MDQ (Beckman Instruments Inc., Fullerton, CA). Separations were carried out at $\mathrm{pH} 3.0$ with a hydrophilic-coated fused-silica capillary (CElect P1, Supelco, Bellefonte, PA) of $0.60 \mathrm{~m} \times 50 \mu \mathrm{m}$, with a slit opening of $100 \times 800 \mu \mathrm{m},(0.50 \mathrm{~m}$ to detection point), at a temperature of $45^{\circ} \mathrm{C}$, with a linear voltage gradient of 0 to $25 \mathrm{kV}$ in $3 \mathrm{~min}$, followed by constant voltage of $25 \mathrm{kV}$. Protein identification was carried out according to Recio et al. (1997).

\section{Plasmin Activity}

The distribution of plasmin and plasmin-derived activity after plasminogen activation by urokinase in the serum and casein fractions of pressurized and unpressurized milks was examined by combining the conventional and modified methodologies proposed by Politis et al. (1993). Skim milk was divided in two aliquots. The first aliquot was incubated with $50 \mathrm{~m} M \varepsilon$-aminocaproic acid ( $\varepsilon$-ACA) (Sigma Chemical Co.) for $2 \mathrm{~h}$ at room temperature to dissociate plasmin and plasminogen from casein micelles and allow their transfer into the serum fraction. The second aliquot was not treated with $\varepsilon$-ACA, so that release of plasmin and plasminogen activities to the serum was not induced. After incubation, the milk samples were ultracentrifuged at $100,000 \times g$ for $1 \mathrm{~h}$ at $4^{\circ} \mathrm{C}$, and the supernatants were carefully removed and filtered as described above.

The casein pellets were reconstituted to the original volume (35 ml) in $50 \mathrm{mM}$ Tris buffer ( $\mathrm{pH} 8.0)$ containing $110 \mathrm{~m} M \mathrm{NaCl}$ and were incubated at room temperature with $50 \mathrm{~m} M \varepsilon$-ACA to allow the transfer to the buffer of plasmin and plasminogen remaining in the casein 
micelles. The casein suspensions were then ultracentrifuged at $100,000 \times g$ for $1 \mathrm{~h}$ at $4^{\circ} \mathrm{C}$, and the filtered supernatants were used for the determination of the enzymatic activities.

Plasmin activity and plasmin-derived activity after plasminogen activation by urokinase were determined by the method originally developed by Rollema et al. (1983) and modified by Korycka-Dahl et al. (1983). Milk serum or buffer $(50 \mu \mathrm{l})$ was mixed with $950 \mu \mathrm{l}$ of 50 $\mathrm{m} M$ Tris buffer ( $\mathrm{pH}$ 7.4) containing $110 \mathrm{~m} M \mathrm{NaCl}, 2.5$ $\mathrm{m} M \varepsilon$-ACA and $0.6 \mathrm{~m} M$ H-D-valyl-L-leucyl-L-lysine- $p$ nitroanilide dihydrochloride (V-0882, Sigma Chemical Co.). For the determination of plasmin-derived activity, 150 plough units of urokinase (U-5004, Sigma Chemical Co.) were also added to achieve plasminogen activation. The reaction mixtures were incubated at $37^{\circ} \mathrm{C}$, and the absorbances at $405 \mathrm{~nm}$ were measured during $3 \mathrm{~h}$ in an ELISA plate reader (Multiskan Ascent, Labsystems, Barcelona, Spain). One unit of activity was defined as the amount of enzyme that produces a change in absorbance of 0.001 in $1 \mathrm{~min}$ under the assay conditions.

\section{Casein Susceptibility to Plasmin Action}

Susceptibility to proteolysis with plasmin was conducted by incubating $10 \mathrm{ml}$ of unpressurized and pressurized skim milks with $75 \mu \mathrm{l}$ of plasmin from bovine plasma (5 I.U./ml, P-7911, Sigma Chemical Co.) at $37^{\circ} \mathrm{C}$ during $90 \mathrm{~min}$. Aliquots $(1 \mathrm{ml})$ were withdrawn from the mixtures at intervals $(0,10,30,60$, and $90 \mathrm{~min})$, and the reactions were stopped by addition of the sample buffer (dilution 1:1.5) used for the CE analysis (Recio and Olieman, 1996).

Changes underwent by unpressurized and pressurized milks on storage, as a result of the action of native plasmin, were compared by keeping milk at refrigeration temperatures $\left(5^{\circ} \mathrm{C}\right)$ in the presence of $30 \mathrm{mM} \mathrm{NaN}{ }_{3}$ as inhibitor of the bacterial growth. Samples were taken for analysis at 2-d intervals for $6 \mathrm{~d}$.

Proteolysis of main caseins and appearance of degradation products was determined by $\mathrm{CE}$ as explained above. For the purpose of normalization, results were expressed as the quotients of the peak areas of the main degradation products: the sum of $\gamma_{2}$-casein $+\gamma_{3}$-casein and $\alpha_{\mathrm{SP}}$-casein divided by the area of $\alpha$-lactalbumin, because the area of this protein did not change as a result of the pressure or enzymatic treatments.

\section{RESULTS}

\section{Pressure-Induced Changes in Micelles and Whey Proteins}

Figure 1 shows transmission electron micrographs of casein micelles in unpressurized skim milk and milks treated at 100, 200, 300, and $400 \mathrm{MPa}$ for $15 \mathrm{~min}$. As a result of pressure, average micelle diameters were reduced from approximately 150 to $300 \mathrm{~nm}$ in unpressurized milk to 75 to $230 \mathrm{~nm}$ in milk pressurized at 100 $\mathrm{MPa}, 100 \mathrm{~nm}$ at $200 \mathrm{MPa}$, and $40 \mathrm{~nm}$ at 300 and 400 $\mathrm{MPa}$. In addition to decreasing micelle dimensions, pressurization led to a narrower size distribution. Thus, the presence in milk treated at $100 \mathrm{MPa}$ of micelles with a size similar to that of the unpressurized milk suggested that only some of the micelles were fragmented, while the high size uniformity found in milk subjected to 300 and $400 \mathrm{MPa}$, indicated that most of the micelles were disrupted at those pressures. Furthermore, clusters of micelles were found in milk pressurized at $300 \mathrm{MPa}$, which were dispersed at $400 \mathrm{MPa}$. A decrease in the average diameter of particles after high-pressure treatment of milk samples at room temperature was already reported, with maximum disruption also occurring at $300 \mathrm{MPa}$ (García-Risco et al., 2000; Needs et al., 2000; Scollard et al., 2000b). Pressure-induced micellar disruption is attributed either to breakage of linkages between casein and inorganic constituents and/or hydrophobic bonds (Schrader et al., 1997).

As a result of micelle disintegration induced by high pressure, an important release of casein to the soluble fraction was produced as shown by CE of the ultracentrifugation supernatants of unpressurized and pressurized milks (Figure 2). The concentration of individual caseins in the ultracentrifugation sera of milks pressurized at 200 and $400 \mathrm{MPa}$ was very similar, despite the differences found in micellar size. This is in agreement with previous results that also showed that maximum levels of nonsedimentable caseins, $\mathrm{Ca}, \mathrm{P}$, and $\mathrm{Mg}$, are found in the serum of milk treated at $300 \mathrm{MPa}$ (LópezFandiño et al., 1998). The individual casein contents were found in the order $\beta$-casein $>\kappa$-casein $>\alpha_{\mathrm{S} 1}$-casein $>\alpha_{\mathrm{S} 0}$-casein $>\alpha_{\mathrm{S} 2}$-casein.

In addition to nonsedimentable caseins, 98 and $80 \%$ of $\beta$-LG remained soluble in ultracentrifugation sera of milks treated at 200 and $400 \mathrm{MPa}$ (Figure 2). Adjustment of the $\mathrm{pH}$ of the ultracentrifugation supernatants to 4.6 revealed that 12 and $78 \%$ of soluble $\beta$-LG was denatured at 200 and $400 \mathrm{MPa}$, respectively.

\section{Plasmin Activity}

Plasmin activity and plasmin-derived activity after plasminogen activation were determined in the serum and casein fractions of milk samples incubated in the absence and presence of $\varepsilon$-ACA (Table 1). In unpressurized milk samples, approximately $85 \%$ of plasmin activity and $82 \%$ of the total plasmin activity produced after plasminogen activation were associated with the casein 

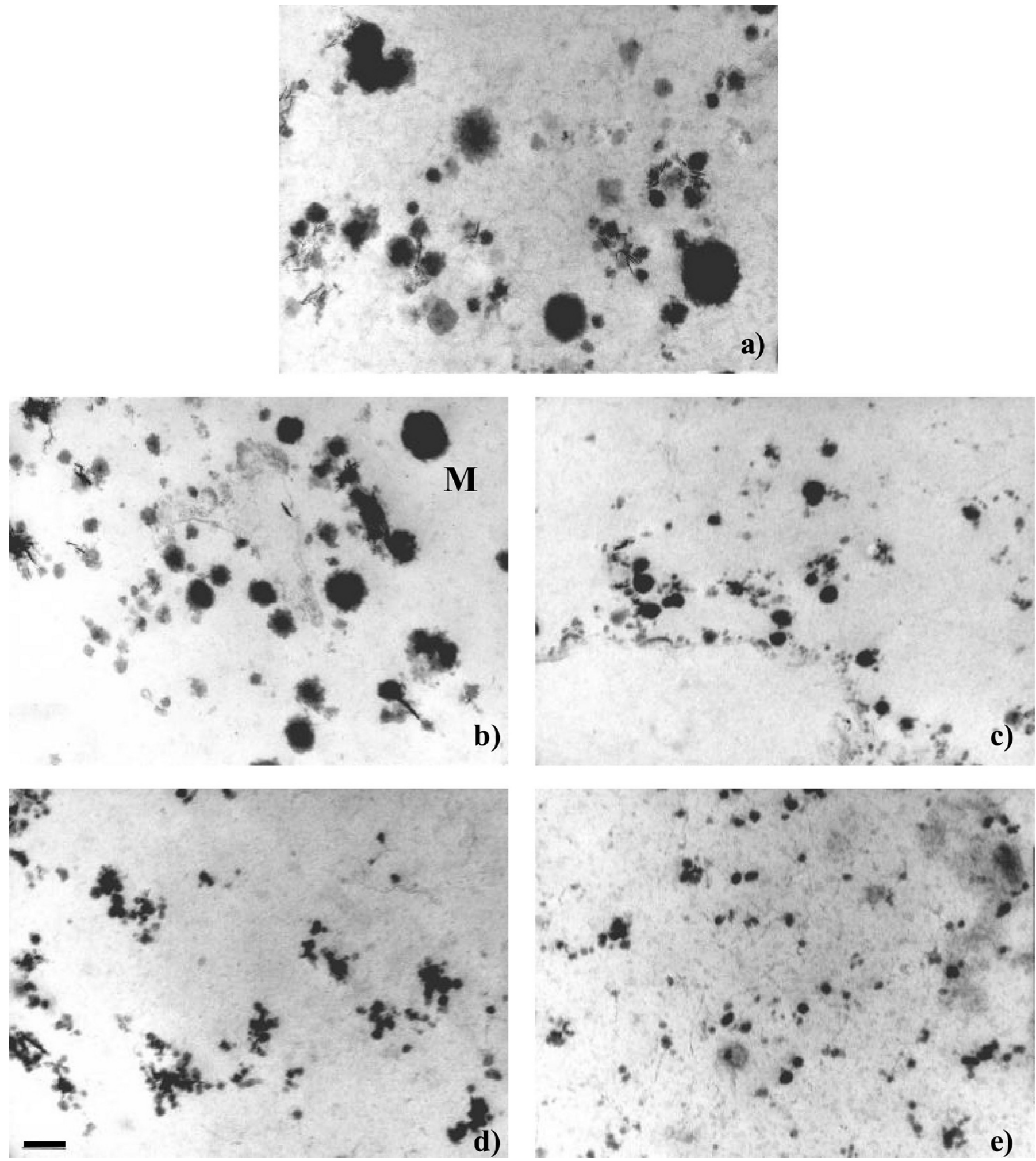

Figure 1. Transmission electron micrographs of unpressurized milk (a) and milk pressurized at 100 (b), 200 (c), 300 (d), and $400 \mathrm{MPa}$ (e). The bar corresponds to $0.2 \mu \mathrm{m}$; M: casein micelle. 

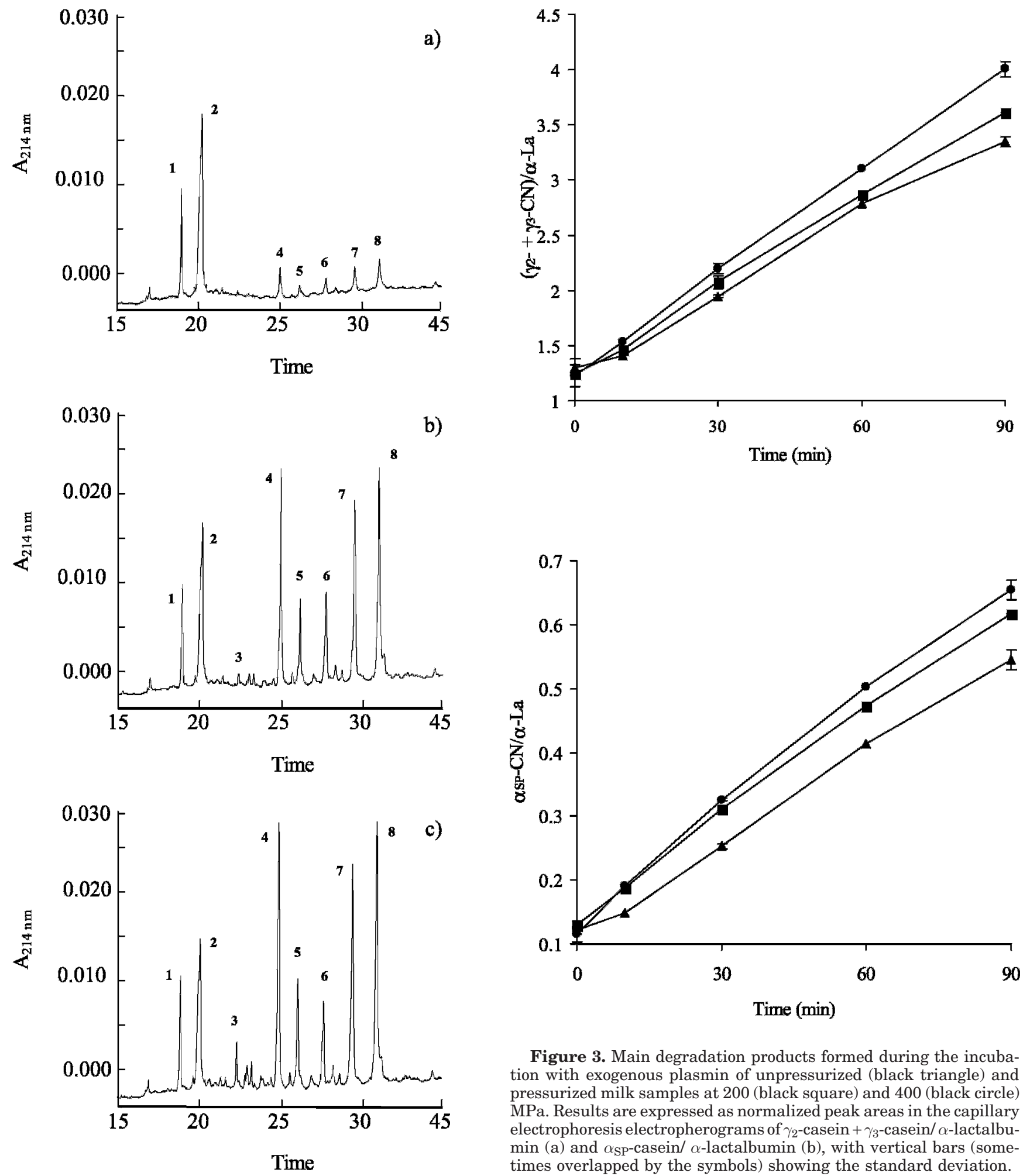

Figure 3. Main degradation products formed during the incubation with exogenous plasmin of unpressurized (black triangle) and pressurized milk samples at 200 (black square) and 400 (black circle) $\mathrm{MPa}$. Results are expressed as normalized peak areas in the capillary electrophoresis electropherograms of $\gamma_{2}$-casein $+\gamma_{3}$-casein/ $\alpha$-lactalbu$\min$ (a) and $\alpha_{\mathrm{SP}}$-casein/ $\alpha$-lactalbumin (b), with vertical bars (sometimes overlapped by the symbols) showing the standard deviation.

Figure 2. Electropherograms of the ultracentrifugation supernatants of unpressurized (a) and pressurized milk at 200 (b), and 400

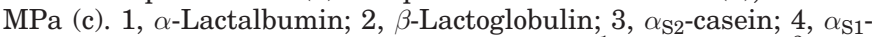
casein; $5, \alpha_{\mathrm{S} 0}$-casein; $6, \kappa$-casein; $7, \beta$-casein $\mathrm{A}^{1} ; 8, \beta$-casein $\mathrm{A}^{2}$. 
Table 1. Plasmin and plasmin-derived activity after plasminogen activation in the serum and reconstituted casein fractions of unpressurized and pressurized milk samples incubated in the absence and presence of $\varepsilon$-aminocaproic acid ( $\varepsilon$-ACA). Results are means followed by standard deviations into brackets.

\begin{tabular}{|c|c|c|c|c|}
\hline \multirow[b]{2}{*}{ Plasmin activity } & \multicolumn{2}{|c|}{$\begin{array}{l}\text { Milk incubated } \\
\text { without } \varepsilon \text {-ACA }\end{array}$} & \multicolumn{2}{|c|}{$\begin{array}{c}\text { Milk } \\
\text { with } \varepsilon-\mathrm{ACA}\end{array}$} \\
\hline & Serum & Casein & Serum & Casein \\
\hline Pressurized $200 \mathrm{MPa}$ & $4.54(0.56)$ & $5.28(0.48)$ & $6.44(1.58)$ & $2.76(0.82)$ \\
\hline Pressurized $400 \mathrm{MPa}$ & $6.86(0.82)$ & $5.12(1.44)$ & $7.12(1.26)$ & $2.18(0.62)$ \\
\hline \multicolumn{5}{|c|}{ Plasmin-derived activity after plasminogen activation } \\
\hline
\end{tabular}

micelles, as revealed by the measurements performed in the absence of $\varepsilon$-ACA. The addition of $\varepsilon$-ACA caused approximately 65 to $75 \%$ of plasmin activity and of the total plasmin activity obtained after plasminogen activation to be transferred to milk serum. The sum of activities in the serum and casein fractions was lower when the milk samples were initially incubated with $\varepsilon$-ACA. This is probably because, in that case, most of the activity was estimated after it was released to the serum, where there are specific inhibitors of the plasmin system (Politis et al., 1993; Precetti et al., 1997).

The measurement of plasmin activity and plasminderived activity after plasminogen activation in the serum phases of milks treated at 200 and $400 \mathrm{MPa}$ that were not incubated with $\varepsilon$-ACA revealed a pressureinduced release of micellar bound enzymes to the serum fractions. Other processes that cause micellar disruption, such as the addition of acids or the growth of psychrotrophic bacteria, also bring about a shift in plasmin from the casein to the whey fraction, which can affect the quality of milk and its derived products (Fajardo-Lira et al., 2000; Hayes and Nielsen, 2000). In samples incubated with $\varepsilon$-ACA, plasmin activities measured in the serum and in the casein fractions of milks pressurized at 200 and $400 \mathrm{MPa}$ were closer to that of the unpressurized milk. This indicates that overall plasmin activity did not change considerably as a result of the pressures applied but underwent a different distribution. In fact, it has been reported that plasmin resists pressures of $400 \mathrm{MPa}$ in milk (García-Risco et al., 2000; Scollard et al., 2000b). Nevertheless, the total plasmin activity after plasminogen activation decreased by 20 to $30 \%$ with pressurization, which is also in agreement with previous results (García-Risco et al., 1998).

\section{Casein Susceptibility to Plasmin Action}

Susceptibility of casein to proteolytic attack was estimated by $\mathrm{CE}$ after incubation with exogenous plasmin for up to $90 \mathrm{~min}$ at $37^{\circ} \mathrm{C}$. As expected, the main degradation products were $\gamma_{2}$ - and $\gamma_{3}$-caseins, that result from the action of the enzyme of $\beta$-caseins, as well as another fragment, named $\alpha_{\mathrm{SP}^{-}}$, that arises from proteolysis of $\alpha_{\mathrm{S} 1}$-casein (Recio et al., 1997). No proteolytic degradation was detected in unpressurized and pressurized milk samples incubated without exogenous plasmin during the same period. Figure 3 illustrates the evolution of those breakdown products during incubation with the enzyme. One-way ANOVA of the data showed that pressurization at 200 and $400 \mathrm{MPa}$ made caseins significantly $(P<0.05 \%)$ more vulnerable to the proteolytic attack. Proteolysis was enhanced in milk treated at $400 \mathrm{MPa}$ over milk pressurized at $200 \mathrm{MPa}(P<$ $0.05 \%$ ).

A slight proteolytic degradation took place in the milk samples during $6 \mathrm{~d}$ of refrigerated storage due to the action of native plasmin, but we did not find significant quantitative differences in the rates of protein breakdown between unpressurized and pressurized milks (results not shown), which is in agreement with previous works (García-Risco et al., 1998; García-Risco et al., 2000). Scollard et al. (2000b) reported that at pressures of 300 to $400 \mathrm{MPa}$ proteolysis was increased relative to raw milk, which also suggested an enhanced availability of substrate bonds to plasmin. However, in that case the statistical signification of the differences observed was not reported.

\section{DISCUSSION}

Our results suggest that pressurization made caseins more susceptible to the proteolytic attack. This is not surprising because pressure caused severe disruption of the micellar structure, releasing high levels of soluble caseins. This can make the access of proteinases to caseins easier and so increase the degree of proteolysis. However, no enhanced proteolytic degradation was observed, when we compared the evolution of pressurized and unpressurized milks during refrigerated storage. 
It should also be noted that, as a consequence of these deep modifications in the micellar structure, not only individual caseins, but also plasmin and plasminogen were released in the soluble fraction of milk on pressurization. Even if the pressure conditions assayed did not lead to plasmin inactivation and only decreased by 20 to $30 \%$ of the total plasmin activity after plasminogen activation, it is likely that serum-liberated enzymes became more vulnerable to the action of proteinase inhibitors normally found in the soluble fraction. This could lead to a diminished proteinase activity that could counteract the enhanced susceptibility of caseins to the enzyme, resulting in proteolysis levels on refrigerated storage similar to those undergone by unpressurized milk.

High levels of soluble denatured $\beta$-LG were found in the ultracentrifugation supernatants of pressurized milks, particularly in those treated at $400 \mathrm{MPa}$. Whether the denatured $\beta$-LG found in the soluble fraction is attached to the pressured-dissociated caseins or polymerized between itself remains unclear. Scollard et al. (2000b), using transmission electron microscopy coupled with immunogold labeling of $\beta$-LG, found $\beta$-LG dots close to disrupted micelle fragments, but definitive evidence for association is lacking. It has been suggested that in $\beta$-LG containing systems pressure inactivation of plasmin may be due to thiol-disulphide bonding with unfolded $\beta$-LG (García-Risco et al., 1998; Scollard et al., 2000a) in a way similar to what occurs when it is exposed to heat (Grufferty and Fox, 1988). Nevertheless, plasmin inactivation does not parallel $\beta$-LG denaturation, the latter being considerably faster (López-Fandiño et al., 1996; Scollard et al., 2000b). Furthermore, plasmin is more pressure resistant in milk than in buffers incorporating $\beta$-LG, which has been attributed to a protective effect due to pressure-induced self-aggregation of $\beta$-LG and/or an increase in the available interaction sites of $\beta$-LG with disrupted casein (Scollard et al., 2000b).

\section{ACKNOWLEDGMENTS}

This research was funded by the project AGL20001497. We also acknowledge Ms. C. Talavera for helpful technical assistance.

\section{REFERENCES}

Bastian, E. D., and R. J. Brown. 1996. Plasmin in milk and dairy products: An update. Int. Dairy J. 6:435-457.

Fajardo-Lira, C., M. Oria, K. D. Hayes, and S. S. Nielsen. 2000. Effect of psychrotrophic bacteria and of an isolated protease from Pseudomonas fluorescens M3/6 on the plasmin system of fresh milk. J. Dairy Sci. 83:2190-2199.

García-Risco, M. R., E. Cortés, A. V. Carrascosa, and R. López-Fandiño. 1998. Microbiological and chemical changes in high-pressure-treated milk during refrigerated storage. J. Food Prot. 61:735-737.

García-Risco, M. R., A. Olano, M. Ramos, and R. López-Fandiño. 2000. Micellar changes induced by high pressure. Influence in the proteolytic activity and organoleptic properties of milk. J. Dairy Sci. 83:2184-2189.

Grufferty, M. B., and P. F. Fox. 1988. Milk alkaline proteinase. J. Dairy Res. 55:609-630.

Hayes, K. D., and S. S. Nielsen. 2000. Plasmin levels in fresh milk whey and commercial whey protein products. J. Dairy Sci. 83:387-394

Huppertz, T., A. L. Kelly, and P. F. Fox. 2002. Effects of high pressure on constituents and properties of milk. Int. Dairy J. 12:561-572.

Korycka-Dahl, M., B. Ribadeau-Dumas, N. Chene, and J. Martal. 1983. Plasmin activity in milk. J. Dairy Sci. 66:704-711.

López-Fandiño, R., A. V. Carrascosa, and A. Olano. 1996. The effects of high pressure on whey protein denaturation and the cheesemaking properties of raw milk. J. Dairy Sci. 79:929-936.

López-Fandiño, R., M. A. de la Fuente, M. Ramos, and A. Olano. 1998. Distribution of minerals and proteins between the soluble and colloidal phases of pressurized milks from different species. J. Dairy Res. 65:69-78.

López-Fandiño, R., and A. Olano. 1998. Effects of high pressures combined with moderate temperatures on the rennet coagulation properties of milk. Int. Dairy J. 8:623-627.

Needs, E. C., R. A. Stenning, A. L. Gill, V. Ferragut, and G. T. Rich. 2000. High pressure treatment of milk: effects on casein micelle structure and on enzymic coagulation. J. Dairy Res. 67:31-42.

Politis, I., B. Zavizion, D. M. Barbano, and R. C. Gorewit. 1993. Enzymatic assay for the combined determination of plasmin plus plasminogen in milk: revisited. J. Dairy Sci. 76:1260-1267.

Precetti, A. S., M. P. Oria, and S. S. Nielsen. 1997. Presence in bovine milk of two protease inhibitors of the plasmin system. J. Dairy Sci. 80:1490-1496.

Recio, I., L. Amigo, M. Ramos, and R. López-Fandiño. 1997. Application of capillary electrophoresis to the study of proteolysis of caseins. J. Dairy Res. 64:221-230.

Recio, I., and C. Olieman. 1996. Determination of denatured serum proteins in the casein fraction of heat-treated milk by capillary zone electrophoresis. Electrophoresis 17:1228-1233.

Rollema, H. S., S. Visser, and J. K. Poll. 1983. Spectrophotometric assay of plasmin and plasminogen in bovine milk. Milchwissenschaft 38:214-217.

Scollard, P. G., T. P. Beresford, P. M. Murphy, and A. L. Kelly. 2000a. Barostability of milk plasmin activity. Lait 80:609-619.

Scollard, P. G., T. P. Beresford, E. C. Needs, P. M. Murphy, and A. L. Kelly. 2000b. Plasmin activity, $\beta$-lactoglobulin denaturation and proteolysis in high pressure treated milk. Int. Dairy J. 10:835-841.

Schrader, K., W. Buchheim, and C. V. Morr. 1997. High pressure effects on the colloidal calcium phosphate and the structural integrity of micellar casein in milk. Part 1. High pressure dissolution of colloidal calcium phosphate in heated milk systems. Nahrung 41:133-138. 